\title{
PROCESSO DE PLANEJAMENTO E DESENVOLVIMENTO DA LOGÍSTICA DE TRANSPORTES
}

\author{
process of planning and development of the transports logistic \\ Luiz Andrei Gonçalves Pereira* \\ Simone Narciso Lessa**
}

\begin{abstract}
Resumo
O processo de planejamento e de desenvolvimento da logística de transportes ampliou as relações capitalistas de produção, favorecendo, assim, a circulação de pessoas, de mercadorias e de informações pelo território brasileiro e norte-mineiro. O objetivo deste trabalho é analisar a configuração da rede logística de transportes e de exportações no processo de planejamento e de desenvolvimento da mesorregião norte de Minas Gerais, sob a perspectiva de ordenamento territorial. Na operacionalização desta pesquisa, utilizaram-se os estudos bibliográficos, os dados de fontes secundárias extraídos de instituições governamentais e a coleta de dados nas fontes primárias, por meio de entrevistas semiestruturadas, que foram aplicadas junto aos representantes do setor de logística ou de comércio exterior das empresas exportadoras, com domicílio fiscal na região norte-mineira. Na política de exportação, aproximadamente $94,5 \%$ dos volumes das cargas, quantidade quilograma, foi transportada por meio de rodovias da área de produção até os entrepostos logísticos. O entreposto logístico mais utilizado é o sistema portuário, que resulta no grande uso do transporte marítimo internacional. A infraestrutura logística de transporte regional necessita de um programa contínuo de investimentos para a recuperação dos gargalos logísticos, e, assim, garantir a viabilização das relações econômicas e sociais intra e inter-regionais.
\end{abstract}

Palavras-chaves: Planejamento regional, desenvolvimento regional, logística de transportes, exportações.

\begin{abstract}
The process of planning and development of the logistics of transport extended the relations of capitalist production, thus establishing better ways for the circulation of persons, goods and information throughout the brazilian country, specially the norte-mineiro region. The aim of this paper is to analyze the network-configuration transportation logistics and exports in the planning process and development of the north of Minas Gerais, from the perspective of regional organization. In this research, we used bibliographical studies, data from secondary sources drawn from government institutions and data on primary sources collected through interviews, which were applied together with representatives of the logistics sector or foreign trade exporting firms with tax residence in the norte-mineira region. On the export business, approximately $94.5 \%$ of the volumes of cargo, quantity kilogram, was transport by road in the area of production to the logistics warehouses. Of these, the harbor is the most used, resulting in great use of international shipping. The regional transport logistic infrastructure requires a continuous investment program for the recovery of logistical difficulties, and thus ensure the viability of economic and social relations within and between regions.
\end{abstract}

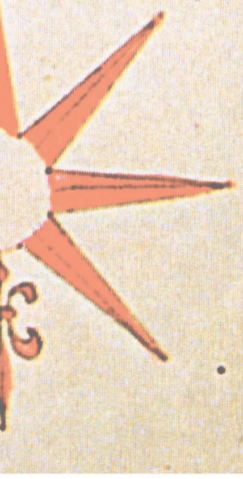

Key words: Regional planning, regional development., transports logistic, exportations.

\section{Resumen}

El proceso de planificación y desarrollo de la logística del transporte ha ampliado las relaciones capitalistas de producción, favoreciendo así, la circulación de personas, bienes e información por territorio brasileño y norte-mineiro. El objetivo de este estudio es analizar la configuración de la red logística de transporte y exportación en el proceso de planificación y desarrollo de la región del Norte de Minas Gerais, desde la perspectiva de la ordenación del territorio. En la puesta en marcha de esta investigación, hemos utilizado los estudios bibliográficos, los datos de fuentes secundarias procedentes de las instituciones gubernamentales y recopilación de datos sobre las fuentes primarias a través de entrevistas, que fueron aplicadas en forma conjunta con los representantes de la industria de la logística y el comercio exterior de empresas exportadoras, con domicilio fiscal en la región norte-mineira. En la política de exportación, aproximadamente el $94,5 \%$ de los volúmenes de carga, cantidad kilogramo, fue transportado a través de carreteras de la zona de producción hasta los terminales logísticos. El terminal logístico más usado es el sistema portuario, que resulta en un gran uso del transporte marítimo internacional. La infraestructura logística de transporte regional necesita de un programa continuo de inversiones para la recuperación de los cuellos de botella logísticos, y asegurar así la viabilidad de las relaciones económicas y sociales dentro y entre regiones.

Palabras-clave: Planificación regional,desarrollo regional, logística de transportes, exportaciones.

(*) Doutorando no Programa de Pós-Graduação em Geografia da Universidade Federal de Uberlândia - Av. João Naves de Ávila, 2121, Bloco H, Campus Sta Mônica, CEP:38.408-100, Uberlândia (MG) - Brasil, Tel. (+ 55 34) 3239.4169 - luizandreigoncalves@ yahoo.com.br

(**) Prof ${ }^{\mathrm{a}}$. Dr ${ }^{\mathrm{a}}$. do Programa de Pós-Graduação em Desenvolvimento Social da Universidade Estadual de Montes Claros Campus Universitário Professor Darcy Ribeiro, Vila Mauricéia, CEP: 39.401-089 - Montes Claros (MG) - Brasil, Tel: (+55 38) 32298149 -monelessa@hotmail.com 


\section{INTRODUÇÃO}

Na política de exportação norte-mineira, o grande desafio é fazer o escoamento das mercadorias do local de produção até os entrepostos logísticos (portos, aeroportos e pontos de fronteiras), uma vez que existe a dependência de uma rede de transporte eficaz e eficiente que possibilite a redução de custos, o aumento de competitividade e a geração de riquezas. Diante do exposto, esta pesquisa buscou responder à seguinte questão: Qual a importância da logística de transportes na formação das redes de exportações, tendo em vista a sua contribuição para o processo de desenvolvimento econômico e social da região norte-mineira? O objetivo deste trabalho é analisar a configuração da rede logística de transportes e de exportações no processo de planejamento e de desenvolvimento da mesorregião norte de Minas Gerais, sob a perspectiva de ordenamento territorial.

O desenvolvimento desta pesquisa se deu em três etapas: Na primeira etapa, os estudos concentraram-se na revisão de literatura, que é o suporte para a discussão dos temas abordados, como: Planejamento regional, desenvolvimento regional, expansão das atividades produtivas, infraestrutura do sistema de transportes e formação das redes de exportações no norte de Minas Gerais.

Na segunda etapa, o trabalho concentrou-se na coleta de dados de fontes secundárias, os quais nos permitiram construir informações a partir de documentos e dos bancos de dados das instituições Departamento Nacional de Infraestrutura de Transportes - DNIT, Departamento de Estradas de Rodagens do Estado de Minas Gerais - DER/MG, Ministério do desenvolvimento, Indústria e Comércio Exterior - MDIC. Essas informações nos possibilitaram contextualizar a política nacional e regional de transportes, bem como configurar as redes de exportações a partir do domicílio fiscal das empresas, localizadas na região norte-mineira.

$\mathrm{Na}$ terceira etapa, desenvolveu-se a pesquisa empírica, com a coleta de dados nas fontes primárias, por meio da aplicação de entrevistas semiestruturadas. A proposta inicial era aplicar as entrevistas junto aos representantes do setor de logística ou de comércio exterior das 50 empresas exportadoras, com domicílios fiscais em 18 municípios, localizadas na mesorregião norte de Minas Gerais (MDIC, 2004 - 2008). No entanto, conseguiu-se entrevistar 45 representantes das empresas exportadoras, cobrindo, aproximadamente, $99,7 \%$ dos valores financeiros, e $99,9 \%$ da quantidade em quilos exportados pela região norte-mineira. As informações extraídas das entrevistas identificaram a modalidade de transporte que cada empresa localizada no norte de Minas utilizou para fazer o percurso do transporte nacional, da unidade de produção até o entreposto logístico. Identificou-se o entreposto logístico alfandegado ou não (portos, portos secos, pontos de fronteira e aeroportos) que a empresa usou para fazer o desembaraço e/ou embarque da mercadoria na modalidade de transporte internacional, para que, posteriormente, as cargas fossem destinadas ao mercado externo. Outro aspecto importante das entrevistas é a análise da percepção dos usuários acerca da infraestrutura da logística de transportes utilizada para ter acesso ao comércio internacional.

\section{PLANEJAMENTO E DESENVOLVIMENTO REGIONAL: o modelo do nordeste brasileiro como referência para o norte de Minas Gerais}

O planejamento regional faz parte da estratégia de desenvolvimento nacional, uma vez que o processo de desenvolvimento nacional deslocou recursos escassos para áreas propícias à atração e reprodução do capital, resultando na concentração de investimentos, que, consequentemente, gerou as disparidades econômicas e sociais regionais:

A escassez de recursos, principalmente capital, a sua utilização é feita de modo concentrado, isto é, procura-se desenvolver um pequeno número de regiões, na esperança de que esse desenvolvimento se disperse, numa fase posterior, pelas demais regiões, compensando-se, assim, os sacrifícios iniciais (HENRIQUES, 1977, p. 464). 
O processo de desenvolvimento é marcado pela concentração, por desequilíbrios e por dualidades. Neste sentido, as políticas de planejamento regional visam corrigir essas distorções geradas pelo planejamento nacional. Nas palavras de Friedman (1977, p. 382), “o planejamento regional está basicamente relacionado à eliminação das características da economia dual, fundindo os dois setores desiguais, de tal forma que uma economia de trocas estenda seu sistema de interação típico por toda área geográfica em questão". O planejamento regional buscou "alcançar um equilíbrio ótimo entre a maximização do crescimento econômico e a minimização dos desequilíbrios regionais entre as diferentes regiões" (ROMO, 1977, p. 395). Sendo assim, Mattos (1977, p. 438) destaca que:

O planejamento regional surge como um processo de decisões e ações que deve incidir sobre os fatores determinantes da conformação do espaço nacional, de maneira a dotá-lo da configuração necessária para o cumprimento de determinados objetivos [...] surge como um instrumento capaz de racionalizar e integrar as decisões que se adotam, com o propósito de alcançar a reestruturação das relações de dominação - dependência que ligam as regiões centrais às periféricas [...] desempenha função análoga a que cumpre o planejamento setorial no processo de planejamento nacional.

Na década de 1930, a questão regional tornou-se um instrumento de intervenção estatal planejada, criando diretrizes para a promoção do desenvolvimento econômico nos países capitalistas ocidentais. Para ilustrar a participação do Estado na política de desenvolvimento regional, citamos como exemplo: Os Estados Unidos, a Europa e o Brasil. Os norte-americanos criaram a Tenessee Valley Authority, que elaborou uma política de planejamento concentrada na intervenção estatal na perspectiva de desenvolver as atividades agrícolas e energéticas na bacia do rio Tenessee. A experiência do planejamento regional norte-americana influenciou outras regiões no mundo, principalmente na Europa e na América Latina. Na Europa, a França implantou os planos de equilíbrio das metrópoles, a Inglaterra implementou a política de desconcentração industrial, e a Itália criou os planos de desenvolvimento para a região do Mezzogiorno, concedendo incentivos fiscais e financeiros para estimular a industrialização no sul da Itália (RODRIGUES, 1999). Esses modelos, dos Estados Unidos e da Itália, influenciaram o modelo de planejamento regional no Brasil.

O desenvolvimento econômico é marcado pelos grandes desequilíbrios regionais, caracterizados pelo processo de desenvolvimento desigual e combinado dentro do sistema capitalista (COHN, 1978). Considerando as desigualdades regionais do país, o governo brasileiro começou a criar instituições de fomento ao desenvolvimento para atuar nas "áreas deprimidas" do seu território. Nesse contexto, o Nordeste, visto como região "problema", tornou-se um "laboratório" para implantação das políticas de desenvolvimento regional. O modelo de desenvolvimento regional brasileiro é constituído basicamente por uma mesclagem da experiência norte-americana e italiana. Como forma de reforçar o argumento anterior, Rodrigues (1999, p. 53) afirma que:

O governo brasileiro, à luz das experiências americana do Vale do Tenessee e da italiana do Vale do Mezzogiorno, cria órgãos para fomentar aquelas regiões menos desenvolvidas do país, como o caso do Nordeste, buscando integrá-la à economia nacional. A SUDENE é inspirada em experiências de planejamento mundial, particularmente as duas citadas acima.

Antecedendo à criação da SUDENE, a região nordestina dispunha de outros órgãos federais que buscavam soluções hidráulicas para resolver os problemas da seca que assolavam essa região, com exceção do Banco do Nordeste. Segundo Cohn (1978), no Nordeste, a atuação do governo federal se dava pelas ações imediatistas de combate aos efeitos da seca, uma vez que se buscavam soluções hidráulicas para os problemas, tais como programas de irrigação, construção de açudes e barragens, perfuração de poços artesianos e destinação de verbas e criação de medidas emergenciais no período de longas estiagens. O órgão pioneiro no combate aos efeitos da seca foi a Inspetoria de Obras Contra as Secas - INFOCS, criada pelo governo federal em 1909, vinculada ao Ministério de Viação e Obras Públicas, transformada em Departamento Nacional de Obras Contra as Secas 
- DNOCS (1946). O DNOCS foi, e é, um órgão planejador e executor de obras de infraestrutura, tarefa que "o referido órgão cumpriu por um extenso programa de transporte e comunicação que assumia um duplo significado: $\mathrm{O}$ de facilitar a integração demográfica e econômica da região, bem como o socorro aos flagelados" (COHN, 1978, p. 59). Em 1936, foi criada a área do "polígono da seca" como forma de ordenar a distribuição dos recursos para os municípios.

Na década de 1940, o governo federal criou mais dois órgãos federais no Nordeste, a Companhia Hidro Elétrica do São Francisco - CHESF (1945) e a Comissão do Vale do São Francisco - CVSF (1948). A CHESF veio realizar o aproveitamento de energia elétrica no rio São Francisco para atender às atividades industriais no Nordeste (BRASIL, DECRETO-LEI No 8.031/1945). A CVSF criou um plano geral de aproveitamento econômico do Vale do São Francisco, visando à regularização do curso de seus rios, à utilização do seu potencial hidroelétrico, à fomentação da indústria e da agricultura, ao desenvolvimento da irrigação, à modernização dos seus meios de transportes, à incrementação da imigração, à colonização, e à prestação de assistência técnica para a exploração de suas riquezas (BRASIL, LEI No 541/1948). Nota-se que a atuação dessas duas instituições desenvolveu a infraestrutura, o potencial hidroelétrico e econômico do Nordeste, buscando atender às necessidades das atividades industriais e agrícolas.

Em 1952, foi criado o Banco do Nordeste do Brasil - BNB, com sede em Fortaleza, prevendo, ainda, a instalação de filiais em diversas áreas do "polígono da seca". O BNB buscava incentivar financeiramente, por meio de empréstimos, o fomento das atividades comerciais, agrícolas e industriais nas áreas que fazem parte desse polígono, além de incluir os investimentos em infraestrutura econômica e urbana (BRASIL, LEI N ${ }^{\circ}$ 1.649/1952). Diferentemente do DNOCS, da CHESF e da CVSF, o BNB "passa a pensar os problemas nordestinos como problemas econômicos e não mais de engenharia hidráulica" (COHN, 1978, p. 61). O BNB é o primeiro órgão federal a ter sede fora da Capital Federal (Rio de Janeiro). A criação do Escritório Técnico de Estudos Econômicos do Nordeste - ETENE realizou estudos e diagnósticos sobre a economia nordestina, evidenciando-se, nos parâmetros do $\mathrm{BNB}$, que os problemas nordestinos não se resumiriam às secas, sendo preciso desenvolver a estrutura produtiva regional, financiando o desenvolvimento dos setores comerciais, agrícolas e industriais (COHN, 1978; FERNANDES, 2006). A partir de 1955, o BNB começou a abrir agências nas áreas do "polígono da seca", inclusive no norte de Minas Gerais.

No governo de Juscelino Kubitschek, o planejamento regional passou a englobar as potencialidades da região nordeste. Ao criar o "Grupo de Trabalho para o Desenvolvimento do Nordeste" - GTDN, foram realizados estudos, diagnósticos e relatórios, os quais resultaram na elaboração do projeto de criação da SUDENE (COHN, 1978). Em 1959, foi criada a "Superintendência do Desenvolvimento do Nordeste" - SUDENE, entrando em funcionamento no ano de 1960. Aárea de abrangência da SUDENE corresponde aos estados do Maranhão, Piauí, Ceará, Rio Grande do Norte, Paraíba, Pernambuco, Alagoas, Sergipe, Bahia e a área do "polígono da seca", no estado de Minas Gerais. Seus objetivos são: Estudar, propor diretrizes e executar projetos para o desenvolvimento do Nordeste, bem como conceder incentivos fiscais para as unidades produtivas instaladas e/ou a serem instaladas nessa região (BRASIL, LEI No 3.692/1959). A SUDENE, no período de 1961 a 1968, elaborou quatro planos diretores para orientar as políticas de desenvolvimento no Nordeste. Os planos diretores I, II, III e IV estabeleciam diretrizes para as ações desta instituição, incluindo os diagnósticos, incentivos às atividades econômicas, investimentos e execução de obras de infraestrutura econômica para propiciar a atração do capital privado nacional e estrangeiro, buscando o desenvolvimento na região nordestina.

A SUDENE serviu de base para a criação de outras instituições de fomento ao desenvolvimento em outras regiões do território brasileiro, como: Superintendência do Desenvolvimento da Amazônia - SUDAM, Banco da Amazônia S/A - BASA, Superintendência do Desenvolvimento do Centro-Oeste - SUDECO e Superintendência do Desenvolvimento do Sul - SUDESUL. Neste sentido, Souza (1979, p. 163) afirma que o "trabalho da SUDENE é o que se refletiu na criação ou reformulação de órgãos e de planos regionais de desenvolvimento para as outras áreas do país, 
como a SUDAM e o BASA, sediados em Belém; a SUDESUL, em Porto Alegre, e a SUDECO, em Brasília". No Nordeste, a atuação conjunta do BNB e da SUDENE foram instrumentos importantes nos incentivos da implementação das políticas de industrialização e de modernização agrícola como parte da estratégia nacional de desenvolvimento. Na transição das décadas de 1960 para 1970, ocorreu a emergência da política de "integração nacional" pela atuação conjunta dessas instituições de fomento em prol do desenvolvimento regional.

Na política de "integração nacional", o foco principal era garantir os investimentos nas áreas "deprimidas" do território brasileiro, incentivando a expansão da infraestrutura econômica, a modernização econômica e a descentralização econômica do eixo Rio - São Paulo. No caso do Nordeste, criaram-se programas específicos de desenvolvimento regional, como o "Programa de Integração Nacional" - PIN (1970), o "Programa de Redistribuição de Terras e de Estímulo Agroindústria do Norte e Nordeste" - PROTERRA (1971) e o "Programa Especial para o Vale do São Francisco" - PROVALE (1972), entre outros, que mantiveram seus investimentos nas áreas de atuação da SUDENE. A criação desses programas resultou no esvaziamento da superintendência e no fortalecimento dos ministérios que decidiam as áreas onde seriam aplicados os recursos (HENRIQUES, 1977). Nesse período, os recursos do "Fundo de Investimentos do Nordeste" - FINOR foram rateados com os outros programas de "integração nacional", o PIN, o PROTERRA e o PROVALE. A SUDENE passou a se dedicar basicamente às tarefas de análise e aprovação de projetos (HENRIQUES, 1977; OLIVEIRA, 2007). A atuação das superintendências de desenvolvimento regional, juntamente com os ministérios do governo central, os governos estaduais e municipais, levou à modernização da infraestrutura econômica e das atividades produtivas regionais em pontos estratégicos do território brasileiro.

A partir dos anos de 1990, as políticas neoliberais, com a "ideia de Estado mínimo", trouxeram novas mudanças para o processo de desenvolvimento regional brasileiro. A primeira delas foi a extinção da SUDECO e SUDESUL, no dia 15 de março de 1990, dia da posse do presidente da república, Fernando Collor de Melo. No início dos anos 2000, o governo de Fernando Henrique Cardoso transformou a SUDENE e a SUDAM em "Agência do Desenvolvimento do Nordeste" - ADENE e "Agência do Desenvolvimento da Amazônia" - ADA, respectivamente. Em 2007, o governo "Lula" extinguiu essas duas agências e reativou novamente as duas superintendências regionais, a nova SUDENE e a nova SUDAM. No início de 2009, esse governo também reativou a SUDECO. Nos planos setoriais dos governos Fernando Collor (1990 - 1992), Itamar Franco (1992 - 1994), Fernando Henrique (1995 - 2002) e "Lula" (2003 - 2010), enfatizaram-se, também, os projetos estruturantes a serem implantados nos chamados "eixos estratégicos de desenvolvimento regional" espalhados pelas regiões norte, nordeste, sudeste, sul e centro-oeste do Brasil.

\section{A POLÍTICA DE PLANEJAMENTO REGIONAL NO NORTE DE MINAS GERAIS: o papel das instituições de fomento ao desenvolvimento}

Oficialmente, em 1911, a mesorregião norte de Minas Gerais foi incorporada à área de abran-

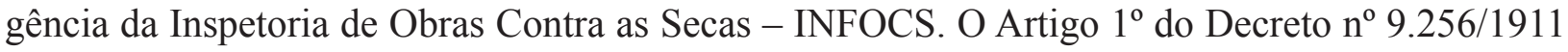
regulamentou os serviços e área de atuação da INFOCS:

Continuarão a cargo da repartição federal denominada Inspectoria de Obras Contra as Seccas os serviços relativos aos estudos e obras contra os effeitos das seccas que assolam alguns Estados do Brazil, comprehendidos entre o Piauhy e o norte de Minas Geraes.

Na política da INFOCS, em 1936, o governo federal criou a área do polígono da seca para ordenar a distribuição dos recursos entre os municípios assolados pelas secas contínuas no nordeste brasileiro. A delimitação desse polígono foi uma forma de se fazer intervenção de caráter imediatista na busca de soluções para minimização dos efeitos das secas. Para isto, investiu-se, principalmente, 
em obras de infraestrutura hidráulica. Em 1946, ocorreu a primeira ampliação do polígono da seca, na qual se incorporou o norte de Minas Gerais. O artigo $1^{\circ}$ do Decreto-Lei $n^{\circ}$ 9.857/1946 transformou a IFOCS em DNOCS e delimitou a nova área do polígono da seca:

A Inspetoria Federal de Obras Contra as Sêcas (I.F.O.C.S.), órgão integrante do Ministério da Viação e Obras Públicas, diretamente subordinado ao Ministro de Estado passa a denominar-se Departamento Nacional de Obras Contra as Sêcas (D.N.O.C.S), com sede na Capital Federal, tem por finalidade a realização de tôdas as obras, destinadas a prevenir e atenuar os efeitos das sêcas na região a que se refere o art. $2^{\circ}$ da Lei $\mathrm{n}^{\circ} 175$, de 7 de Janeiro de 1936, na área compreendida entre a margem direita do rio São Francisco desde Barra, no Estado da Bahia, até Pirapora, no Estado de Minas Gerais, a linha Pirapora - Montes Claros e a linha Montes Claros - Amargosa, no Estado da Bahia, e em outras zonas do país, a que a lei venha a estender o seu campo de ação (sic).

A partir de 1946, o DNOCS passou a atuar de forma mais efetiva na região norte-mineira; consequentemente, em 1948, abriu seu escritório na cidade de Montes Claros, para atuar na execução de obras de infraestrutura, buscando atenuar os efeitos da seca nessa região. $\mathrm{O}$ artigo $1^{\circ}$ da Lei $\mathrm{n}^{\mathrm{o}}$ 1.348/1951 delimitou mais uma vez a área do polígono da seca. Pela linha atual, foram incluídas as "cidades de Pirapora, Bocaiuva, Salinas e Rio Pardo de Minas, no estado de Minas Gerais". Na região, as obras executadas pelo DNOCS foram: A construção de açudes, a perfuração de poços artesianos, o serviço de distribuição de água, o serviço de esgoto, a abertura de estradas de rodagens e a construção de pontes para dar acesso aos açudes.

O Banco do Nordeste do Brasil - BNB, criado em 1952, é outro órgão federal que passou a atuar também na área do polígono da seca. Em 1955, o BNB começou a abrir as suas primeiras agências no norte de Minas, visando incentivar, financeiramente, as atividades comerciais, agrícolas e industriais. A assessoria de comunicação do BNB destacou que, na região norte-mineira, a primeira agência foi aberta em Montes Claros (1955). Posteriormente, abriram-se outras agências em Porteirinha (1959), Januária (1959), Salinas (1968), Brasília de Minas (1969), Pirapora (1975), Monte Azul (1977), Montalvânia (1978) e Janaúba (1982). A atuação do Banco do Nordeste, no norte de Minas, incentivou, com recursos financeiros, os projetos de infraestrutura, industriais e agrícolas, principalmente aqueles projetos elaborados e aprovados pela Superintendência do Desenvolvimento do Nordeste - SUDENE.

A SUDENE, criada em 1959, tinha como propósito a incorporação da área mineira do polígono da seca. Entretanto, nas diretrizes do seu "I Plano Diretor" (1961 - 1963), o norte de Minas foi excluído. O critério para esta exclusão é explicado pela divisão político-administrativa, que obedecia aos limites estaduais. Sendo assim, a área da SUDENE correspondia aos estados do Maranhão, Piauí, Ceará, Rio Grande do Norte, Paraíba, Pernambuco, Alagoas, Sergipe e Bahia (OLIVEIRA, 2000; SUDENE, 1966 a). Oficialmente, em 1963, o "II Plano Diretor" (1963 - 1965) incluiu a região norte-mineira na área de atuação da SUDENE. Esse plano propunha investir em infraestrutura econômica, direcionando os recursos para a construção e a pavimentação de estradas, para a ampliação e os melhoramentos no sistema de energia e de comunicações, além de garantir investimentos no sistema de distribuição de água e nos serviços de esgotos (SUDENE, 1968 a). Em 1965, a SUDENE inaugurou seu escritório na cidade de Montes Claros.

No seu "III Plano Diretor" (1966 - 1968), a SUDENE propunha investimento em infraestrutura econômica, como a ampliação do sistema Três Marias de distribuição de energia na área mineira do polígono da seca; a construção e a pavimentação das rodovias federais na região (BR 030, BR 135, BR 251, BR 122 e BR 342); a elaboração de projetos de rede de esgoto; a ampliação do sistema de distribuição de água e dos serviços de esgoto; e investimentos em educação (SUDENE, 1966 b). No "IV Plano Diretor" (1969 - 1973), foram propostas a ampliação dos serviços de distribuição de água, da rede de esgoto e da rede de transmissão de energia, a pavimentação de rodovias, a implantação de projetos de agricultura irrigada e a expansão das atividades industriais (SUDENE, 1968 b). 
A atuação conjunta da SUDENE com outros órgãos dos governos federal, estadual e municipal propiciou a abertura das estradas de rodagens, a implantação dos serviços de distribuição de água, a implantação da rede de esgoto, a ampliação da rede de comunicação e de distribuição de energia, e a concessão de incentivos fiscais e financeiros para a viabilização das políticas de desenvolvimento regional. No setor de transportes, somente no início dos anos de 1970 ocorreram a construção e a pavimentação das rodovias federais, para atender diretamente à região norte-mineira. Grande parte dessas obras rodoviárias foi executada com recursos do Departamento Nacional de Estradas de Rodagens - DNER, da SUDENE, do BNB, do Banco Nacional de Desenvolvimento Econômico BNDE (sendo transformado, em 1982, no Banco Nacional de Desenvolvimento Econômico e Social - BNDES), do Programa Especial para o Vale do São Francisco - PROVALE e do Departamento Estadual de Estradas de Rodagens de Minas Gerais - DER/MG.

Na região norte-mineira, a Companhia de Desenvolvimento do Vale do São Francisco e Parnaíba - CODEVASF incentivou também os investimentos em infraestrutura econômica e o aproveitamento econômico do vale do São Francisco, originando os projetos de agricultura irrigada regionais, como os Projetos Jaíba, Gorutuba, Lagoa Grande, Pirapora, entre outros (GEIPOT, 2001; RODRIGUES, 2000). A atuação das instituições estatais viabilizou a implantação da política de desenvolvimento regional e a modernização econômica do norte de Minas, assunto da próxima seção.

\section{AS AÇÕES ESTATAIS NO PROCESSO DE DESENVOLVIMENTO REGIONAL: A expansão das atividades produtivas no norte de Minas Gerais}

A descentralização econômica do eixo Rio - São Paulo levou o governo federal a elaborar planos de desenvolvimento regional para as áreas periféricas do território brasileiro. As ações estatais favorecem o investimento em infraestrutura, a criação e/ou intensificação da atuação das instituições de fomento e a concessão de incentivos fiscais e financeiros para a viabilização das políticas de modernização econômica. Os órgãos federais tiveram um papel importante na elaboração e na implantação dos projetos de desenvolvimento industriais, agrícolas e agroindustriais na região nordestina e norte-mineira.

No caso do norte de Minas, houve, também, a atuação das instituições do estado de Minas Gerais. Em relação às instituições estaduais, podem-se destacar: O DER - MG, a Companhia Energética de Minas Gerais - CEMIG, o Banco Nacional de Desenvolvimento de Minas Gerais BDMG, a Fundação Rural Mineira - RURALMINAS, o Instituto de Desenvolvimento Integrado de Minas Gerais - INDI, a Empresa de Pesquisa Agropecuária de Minas Gerais - EPAMIG, e a Empresa de Assistência Técnica e Extensão Rural do Estado de Minas Gerais - EMATER/MG, entre outras. Conforme Pereira, A. (2007, p. 110), na região norte-mineira, "os incentivos do poder público, estadual e federal, foram destinados à modernização do campo e à industrialização. No campo, os investimentos concentraram-se nas fazendas de criação de gado, nos grandes projetos de irrigação e nas atividades de reflorestamento". As ações das instituições estatais federais e estaduais resultaram na ampliação da infraestrutura e na modernização econômica do norte de Minas Gerais.

No processo de descentralização econômica, o capital buscou formas alternativas de reprodução, visando à desoneração dos custos produtivos, e, assim, favorecendo a expansão do sistema capitalista pelo interior do país, principalmente nas regiões e/ou cidades mais bem dotadas de infraestrutura de transporte, de energia e de comunicações. No norte de Minas, a expansão da infraestrutura econômica se deu pelos investimentos públicos federais na reestruturação do sistema ferroviário, na construção e na pavimentação de rodovias. O governo de Minas, em parceria com o governo federal, investiu na construção e na pavimentação de estradas de rodagens, na expansão do sistema de distribuição de energia e de telefonia. A participação estatal viabilizou os investimentos nas áreas de infraestrutura econômica, modernizou os setores tradicionais da economia, atraindo investimentos privados por meio da concessão de incentivos fiscais e financeiros aos empreen- 
dimentos industriais, agropecuários e agroindustriais instalados ou a serem instalados na região (PEREIRA, L. 2007; REIS, 1997; OLIVEIRA, 2000).

Considerando a importância dos incentivos fiscais e financeiros na atração de capital privado para a região, os "Planos Diretores da SUDENE", em seus artigos 34 e 18 - Fundo de Investimentos do Nordeste-FINOR, foram instrumentos importantes no processo de desenvolvimento regional. O artigo 34 prevê a redução de tributos para as atividades industriais nacionais, e o artigo 18 estende esse benefício ao capital estrangeiro e aos projetos agropecuários. Os incentivos fiscais foram: A isenção total do imposto de renda por 10 a 15 anos para as novas empresas a serem instaladas na região; a redução de impostos para as empresas que atuam na região; a isenção de tarifas de importações; a isenção de taxas bancárias e a isenção do Imposto sobre Circulação de Mercadorias e Serviços - ICMS. Complementando o processo de modernização econômica, o Banco do Nordeste financiou os projetos prioritários com juros de $12 \%$ ao ano, valor inferior à inflação no período. Para os projetos classificados como prioritários, o BNB financiaria até 50\%, a SUDENE/FINOR 37,5\%, e o investidor empresário $12,5 \%$ do capital a ser investido no novo empreendimento a ser instalado na região norte-mineira. Acrescentam-se, também, a isenção de impostos municipais e a doação de terrenos por parte dos municípios aos novos empreendimentos industriais (OLIVEIRA, 2000; 1996). As ações estatais, por meio da SUDENE (incentivos fiscais), do BNB (financiamento), do governo de Minas e dos municípios, favoreceram a ampliação da infraestrutura econômica e a implantação de novos empreendimentos industriais, agropecuários e agroindustriais no norte de Minas Gerais.

No final dos anos 1960, as ações das instituições estatais propiciaram a implantação do parque industrial na cidade de Montes Claros. Posteriormente, expandiu-se para outras cidades, como Pirapora, Várzea da Palma, Bocaiuva e Capitão Enéas. Para a Fundação João Pinheiro - FJP (1975), Reis (1997), Rodrigues (2000), Oliveira (2000), a expansão do capital ocorreu de forma concentrada no norte de Minas, pois apenas as cidades mais bem dotadas de infraestrutura conseguiram desenvolver seu parque industrial. No norte de Minas, uma das cidades que mais se beneficiou como esse projeto foi a cidade de Montes Claros, por apresentar melhor infraestrutura econômica e urbana, se comparada às outras cidades da região. Outras cidades da região também desenvolveram os seus projetos agropecuário-agroindustriais, com destaque para os principais incentivos à pecuária, nos municípios de Buritizeiro, Janaúba e Varzelândia; à silvicultura, nos municípios de Lassance, Grão-Mogol, São João do Paraíso e Rio Pardo de Minas, entre outros, e à agricultura irrigada, nos municípios de Janaúba, Jaíba/Matias Cardoso, Nova Porteirinha e Pirapora.

No processo de centralização do sistema capitalista, foram poucas as cidades que conseguiram desenvolver seus parques industriais e projetos agropecuários-agroindustriais, pois estes exigiam infraestrutura nas áreas de energia, de transporte e de comunicações. Na política de desenvolvimento regional, tornou-se necessário investir em infraestrutura para a viabilização do processo de expansão do capital. No sistema capitalista, o papel do sistema de transporte é interagir e integrar as articulações entre as bases produtivas regional, nacional e internacional. Os investimentos nos setores de infraestrutura econômica, associados à concessão de incentivos fiscais e financeiros, contribuíram para a expansão do capital privado no norte de Minas, que concentrou as suas atividades produtivas em alguns poucos pontos do território regional.

Na região norte-mineira, a expansão do capital, representado pela industrialização, ocorreu, na sua grande maioria, nos municípios que dispunham, simultaneamente, das redes de transportes terrestres ferroviários e rodoviários. Neste sentido, destaca-se o ordenamento da distribuição das atividades produtivas nos municípios de Montes Claros (BR 135, BR 365, BR 251 e FCA), Pirapora (BR 365, BR 496 e FCA), Bocaiuva (BR 135, BR 451 e FCA), Várzea da Palma (BR 496 e FCA) e Capitão Enéas (BR 122 e FCA). No setor agroindustrial (agricultura irrigada), também se encontra a presença simultânea da ferrovia e da rodovia nos projetos de irrigação de Pirapora (BR 365, BR 496 e FCA), Lagoa Grande e Gorutuba (Janaúba: BR 122 e FCA). Entretanto, o acesso ao Projeto Jaíba e aos projetos de silvicultura se dá apenas pelo sistema rodoviário. A figura 1 mostra a espa- 
cialização do sistema de transportes terrestres, associado à expansão dos eixos de desenvolvimento industrial, agropecuário e agroindustrial da região norte de Minas Gerais.

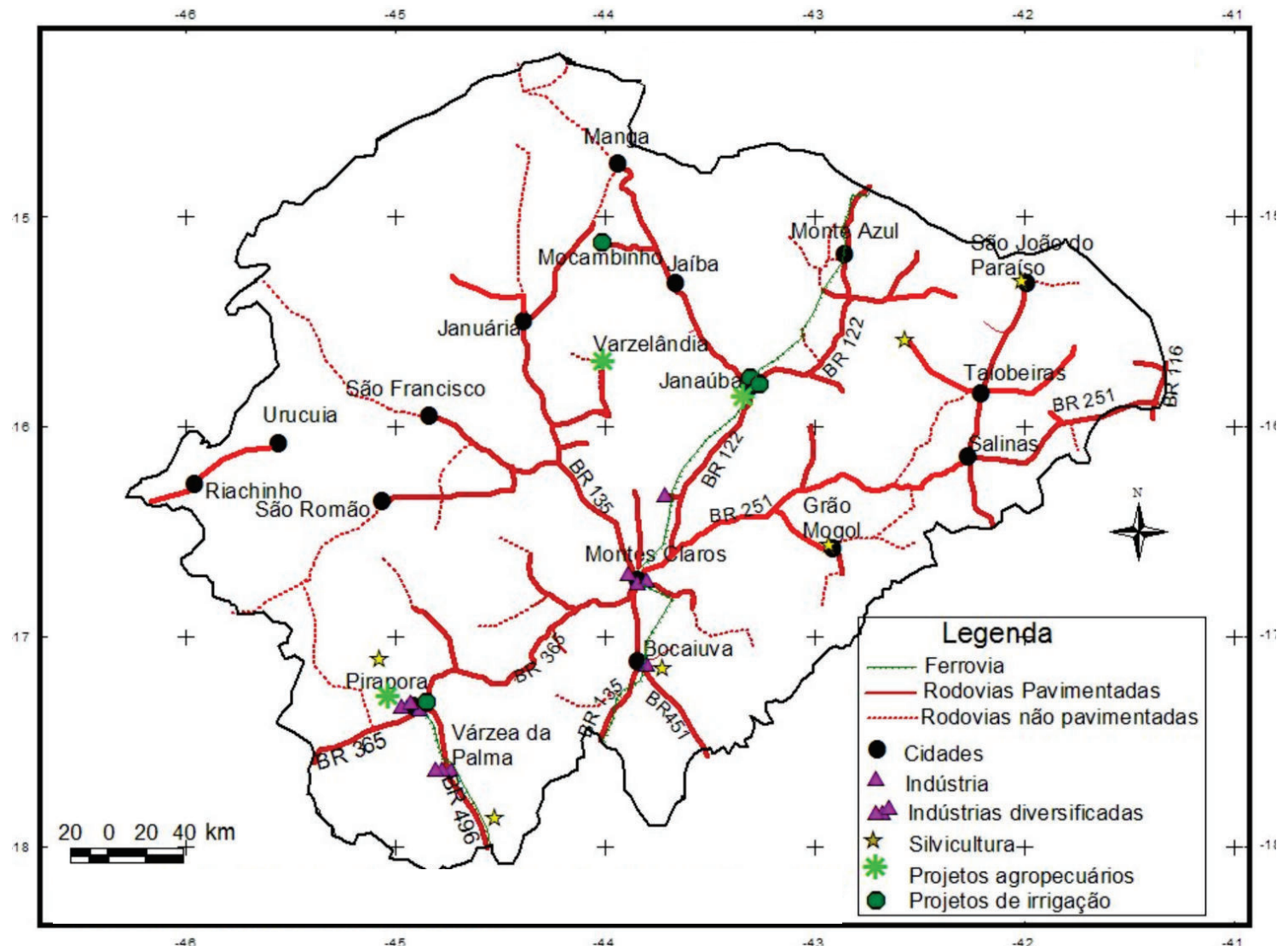

Figura 1 - Mapa do Norte de Minas: Transportes terrestres e os eixos de desenvolvimento Fonte: DER - MG, 2009. FJP, 1975. OLIVEIRA, M. F. M., 2000. RODRIGUES, L., 2000.

Org. PEREIRA, Luiz Andrei Gonçalves, 2008.

No processo de ordenamento territorial da região norte-mineira, a SUDENE transformou a infraestrutura econômica regional e viabilizou o processo de modernização econômica. Entretanto, ao longo da sua história, a SUDENE sofreu inúmeras críticas na viabilização do processo de desenvolvimento regional, tais como: A) Incentivo e financiamento de médios e grandes empreendimentos industriais, agrícolas e agroindustriais organizados em Sociedade Anônima, excluindo grande parte das empresas locais. B) Esvaziamento dos recursos do FINOR, que foram divididos com PIN e PROTERRA. C) A renúncia fiscal beneficiou grandes empresários de outras regiões, especialmente paulistas, em detrimento dos pequenos empresários regionais, resultando na transferência de hegemonia para empresários do centro-sul. D) Investimentos nas atividades produtivas, agrícolas e industriais, que usam e/ou usaram muita tecnologia, poupando mão-de-obra e não gerando a quantidade de empregos prometidos (MONTES CLAROS, 1978; RODRIGUES, 2000; OLIVEIRA, 2000).

Os incentivos fiscais e financeiros atraíram empresas privadas para a região em estudo, destacando-se os setores de frigorífico, de pecuária, de siderurgia, de metalurgia, de alimentação, de bebidas, de reflorestamento, de biotecnologia e de equipamentos, que desenvolveram as suas atividades produtivas principalmente por meio dos subsídios estatais. O processo de modernização econômica viabilizado pela SUDENE incentivou a instalação de empresas privadas nos municípios norte-mineiros. Entretanto, a redução de subsídios ou o fim de alguns deles deixou a região menos atrativa ao capital privado. Nesse processo, as filiais de grandes empresas foram fechadas no norte de Minas, como exemplos da Coca-Cola, Vilma, Aymoré, Antárctica, entre outras, que, durante o processo dos subsídios, investiram na modernização de suas estruturas produtivas localizadas em 
outras regiões do país, e, com o fechamento de suas filiais nos municípios norte-mineiros, mantiveram a sua estrutura na escala produtiva. Durante a política de incentivos fiscais e financeiros, algumas empresas declararam falência, como: Frigodias, Frigonorte, Meca, Santa Rosa, Oscar Nordeste, Sion, entre outras. Há também, grandes empresas privadas localizadas nesta região que receberam e/ou recebem os benefícios fiscais e financeiros, modernizando-se tecnologicamente e ampliando a sua linha de produção. Algumas foram compradas por grupos transnacionais, são os grandes grupos empresariais que atuam na região norte-mineira.

Atualmente, no norte de Minas, os incentivos fiscais beneficiam a implantação, a modernização, a ampliação e a diversificação dos empreendimentos privados, com as seguintes medidas: Redução de 75\% do imposto de renda, pelo prazo de 10 (dez) anos; redução do imposto de renda em 25\%, até 2008 , e $12,5 \%$, a partir de 2009, para os empreendimentos existentes; reinvestimento de até 30\% do imposto de renda devido nos projetos de modernização ou complementação de equipamentos; isenção do Adicional ao Frete para Renovação da Marinha Mercante - AFRMM, e a isenção do Imposto sobre Operações Financeiras - IOF nas operações de câmbio realizadas para pagamento de bens importados, entre outros. No setor de financiamento, o fundo de investimento da nova SUDENE, gerenciado pelo BNB, beneficia, por meio de empréstimos, as obras de infraestrutura para as empresas de tecnologia, de agricultura, de mineração e indústrias diversas (SUDENE, 2009).

O processo de modernização viabilizado pelas ações estatais favoreceu a expansão do capital privado, que se deu de forma seletiva e concentrada. Essa concentração é notória nos municípios que apresentam melhor infraestrutura em transportes, em energia e em comunicações. As mudanças ocorridas na estrutura ferroviária e rodoviária, a partir de 1970, têm demonstrado melhorias na infraestrutura de transporte terrestre. No entanto, nas décadas seguintes, a falta de, ou os baixos investimentos na recuperação desta infraestrutura, tem levado a malha rodoviária e ferroviária ao sucateamento. Sendo assim, a região norte-mineira apresenta estrangulamentos nos setores de logística e transportes, que exigiu e continua a exigir programas contínuos de investimentos na melhoria da infraestrutura regional, para que possa atrair mais investimentos privados para a região.

\section{O COMÉRCIO INTERNACIONAL NO PROCESSO DE DESENVOLVIMENTO REGIONAL NORTE-MINEIRO: A logística de transportes dos setores exportadores}

O desenvolvimento da infraestrutura econômica propiciou a expansão concentrada das atividades produtivas na mesorregião norte de Minas Gerais. A implantação dos eixos de desenvolvimento industriais, agrícolas e agroindustriais ampliou as relações comerciais da região norte-mineira com os demais mercados nacionais e internacionais. A política de exportações da região norte-mineira levou à identificação e à análise dos valores financeiros da balança comercial regional, para que, posteriormente, fosse feita uma caracterização dos municípios, dos produtos e dos setores exportadores, considerando os valores monetários e a quantidade em peso da produção exportada. A balança comercial norte-mineira apresentou um crescimento significativo de 2004 a 2006, apresentando queda no ano de 2007 e 2008. Mas, no período de 2004 - 2008, a balança comercial regional apresentou superavit. Na composição da balança comercial, as exportações apresentaram um leve crescimento contínuo, enquanto as importações tiveram variações bruscas no processo de crescimento ou de queda. Essas informações estão destacadas na tabela 1.

$\mathrm{Na}$ política de exportação regional, existe diferença entre os municípios norte-mineiros na forma de sua inserção nas redes de exportações, sendo que, dos 89 municípios da região, apenas 18 conseguiram exportar a sua produção para os principais mercados internacionais. A figura 2 visualiza a espacialização dos municípios exportadores da mesorregião norte de Minas Gerais. 
Tabela 1 - Norte de Minas: Desempenho da balança comercial no período de 2004 - 2008 (US\$/FOB)

\begin{tabular}{r|c|c|c|c|c|c}
\hline \multicolumn{1}{c|}{ ANO } & EXPORTAÇÃO & VARIAÇÃO \% & IMPORTAÇÃO & VARIAÇÃO\% & BALANÇA COMERCIAL & VARIAÇÃO \% \\
\hline $\mathbf{2 0 0 4}$ & 255.335 .045 & - & 44.642 .310 & - & 210.692 .735 & - \\
\hline $\mathbf{2 0 0 5}$ & 299.470 .786 & 17 & 81.347 .291 & 85 & 218.123 .495 & 4 \\
\hline $\mathbf{2 0 0 6}$ & 360.861 .182 & 21 & 80.544 .362 & -1 & 280.316 .820 & 28 \\
\hline $\mathbf{2 0 0 7}$ & 439.885 .671 & 22 & 122.030 .358 & 52 & 317.854 .813 & 13 \\
\hline $\mathbf{2 0 0 8}$ & 544.881 .451 & 24 & 199.110 .751 & 64 & 345.770 .700 & 9 \\
\hline
\end{tabular}

Fonte: MDIC, 2004; 2005; 2006; 2007; 2008. Org. PEREIRA, Luiz Andrei Gonçalves, 2009.

Na análise dos municípios exportadores no período de 2004 a 2008 (moeda corrente), observa-se que os municípios de Pirapora, Montes Claros, Várzea da Palma, Capitão Enéas e Bocaiuva exportaram, individualmente, valores superiores a US\$ 50.000.000. Juntos, esses municípios exportaram US\$ 1.863.576.134. Desses municípios, Pirapora, Montes Claros e Várzea da Palma foram os maiores exportadores da região, somando um valor de US\$1.606.948.171. O município que exportou, individualmente, na faixa de US\$10.000.000 a US\$ 50.000.000 foi Janaúba, com US\$ 17.253.408. Os municípios de Grão-Mogol, Olhos D’ Água, São João do Paraíso, Salinas e Vargem Grande do Rio Pardo exportaram, individualmente, na faixa de valor entre US\$1.000.000 e 10.000.000; no total, exportaram US\$ 17.544.885. Outros municípios exportaram, individualmente, valores inferiores a US\$ 1.000.000: Águas Vermelhas, Taiobeiras, Ninheira, Curral de Dentro, Divisa Alegre, Manga e Coração de Jesus, os quais exportaram US\$ 2.059.708. Nesse período, a região norte de Minas exportou um total de US\$ 1.900.434.135. Essas informações podem ser observadas na tabela 2, que aponta os municípios exportadores da região norte-mineira, no período de $2004-2008$.

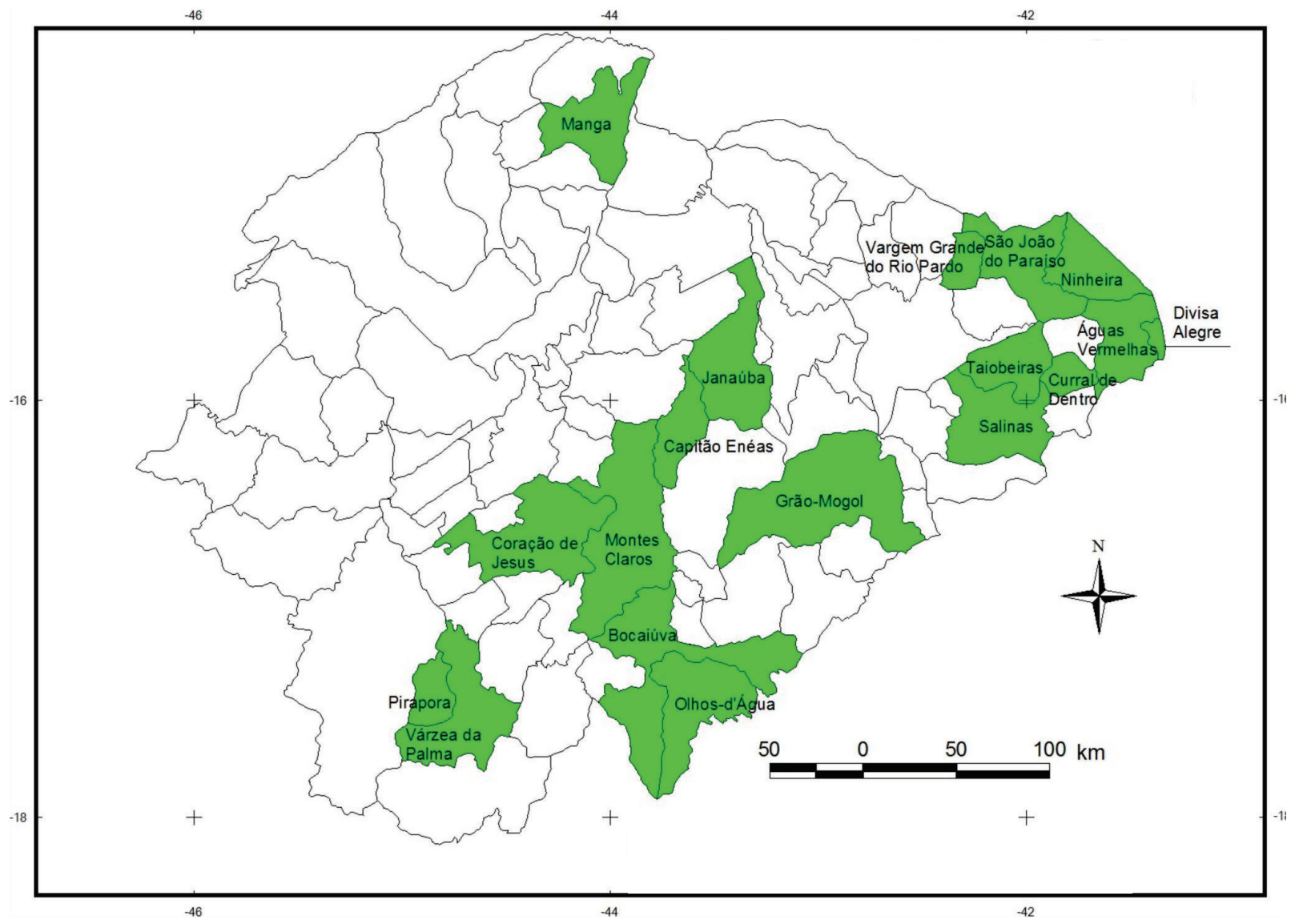

Figura 2 - Mapa do Norte de Minas: Municípios exportadores de 2004 a 2008.

Fonte: MDIC, 2004; 2005; 2006; 2007; 2008.

Org. PEREIRA, Luiz Andrei Gonçalves, 2008. 
Tabela 2 - Norte de Minas Gerais: Municípios exportadores no período de 2004 - 2008 (US\$/FOB)

\begin{tabular}{|c|c|c|c|c|c|c|}
\hline MUNICÍPIOS/ANO & 2004 & 2005 & 2006 & 2007 & 2008 & TOTAL \\
\hline Pirapora & 89.342 .970 & 103.434 .756 & 112.583 .606 & 149.471 .344 & 195.368 .070 & 650.200 .746 \\
\hline Montes Claros & 72.919 .557 & 85.640 .400 & 147.425 .370 & 161.742 .110 & 176.519 .958 & 644.247.395 \\
\hline Várzea da Palma & 54.290 .048 & 62.350 .431 & 44.900 .362 & 62.476 .098 & 88.483 .091 & 312.500 .030 \\
\hline Capitão Enéas & 27.583 .476 & 34.027 .662 & 35.586 .439 & 40.684 .728 & 44.413 .141 & 182.295 .446 \\
\hline Bocaiuva & 7.352 .571 & 10.777 .330 & 11.297.667 & 16.839 .155 & 28.065 .794 & 74.332.517 \\
\hline Janaúba & 74.180 & 93.317 & 6.372 .395 & 4.999.191 & 5.714 .325 & 17.253 .408 \\
\hline Olhos D’Água & - & - & - & 1.115 .055 & 4.904 .585 & 6.019 .640 \\
\hline São João do Paraíso & 587.175 & 893.823 & 1.116 .463 & 1.251 .741 & 495.822 & 4.345 .024 \\
\hline Grão-Mogol & 1.171 .055 & 1.132 .462 & 888.345 & 593.316 & - & 3.785 .178 \\
\hline Vargem G. Rio Pardo & 1.243 .190 & 277.473 & 279.162 & 248.418 & 283.264 & 2.331 .507 \\
\hline Salinas & 161.331 & 128.590 & 120.159 & 244.550 & 408.906 & 1.063 .536 \\
\hline Taiobeiras & 511.519 & 224.661 & 36.142 & 94.378 & 84.539 & 951.239 \\
\hline Curral de Dentro & - & 23.383 & 110.054 & 125.279 & 12.407 & 271.123 \\
\hline Ninheira & 11.800 & 350.861 & 145.018 & 308 & - & 507.987 \\
\hline Manga & 86.173 & 71.844 & - & - & - & 158.017 \\
\hline Águas Vermelhas & - & - & - & - & 93.090 & 93.090 \\
\hline Coração de Jesus & - & 43.793 & - & - & - & 43.793 \\
\hline Divisa Alegre & - & - & - & - & 34.459 & 34.459 \\
\hline Norte de Minas & 255.335.045 & 299.470 .786 & 360.861 .182 & 439.885 .671 & 544.881 .451 & 1.900 .434 .135 \\
\hline
\end{tabular}

Fonte: MDIC, 2004; 2005; 2006; 2007; 2008.

Org. PEREIRA, Luiz Andrei Gonçalves, 2009.

Os principais produtos exportados pelas empresas localizadas na mesorregião norte de Minas foram: Silício, ferroligas, ferrossilício, blocos de motores, hidrômetros, parafusos, pinos de aço, peças automotivas, placas ferroviárias, material de precisão, corpos roedores (esferas), tecidos, vestuário, produtos veterinários, insulina, enzimas, comprimidos, cachaça, leite condensado, embalagens, madeiras, arcos de madeira, óleo de eucalipto, óculos, frutas, polpa de frutas, polpa de tomate, carne bovina, granito, diamante, entre outros. Esses produtos são fabricados por empresas privadas localizadas em Pirapora (indústria: Siderúrgica e têxtil), Montes Claros (indústria: Têxtil, químico-farmacêutica, metalurgia, entre outras), Várzea da Palma (indústria: Siderúrgica e metalúrgica), Capitão Enéas (indústria siderúrgica), Bocaiuva (indústria siderúrgica e metalúrgica), Janaúba (indústria: Frigorífico, entre outras), Grão-Mogol (madeira de eucalipto), Salinas, Taiobeiras, São João do Paraíso, Vargem Grande do Rio Pardo, São João do Paraíso, Olhos D`Água, Curral de Dentro, Águas Vermelhas, Ninheira, Divisa Alegre, Manga e Coração de Jesus (Cachaça, frutas, polpa de frutas, madeira de eucalipto, óleo de eucalipto, granito, diamante, entre outras).

Analisando os números percentuais dos valores financeiros (moeda corrente/dólar), exportados por cada setor da região norte-mineira, percebe-se que os setores siderúrgico/metalúrgico representou $62,25 \%$; têxtil/vestuário, $23,85 \%$; químico-farmacêutico, $11,46 \%$; frigorífico, $0,88 \%$; madeira/ derivados, $0,49 \%$; mineração, $0,35 \%$; fruticultura, $0,17 \%$; cachaça, $0,04 \%$; e outros, $0,51 \%$. Valores percentuais da quantidade quilograma exportados por cada setor: O setor siderúrgico/metalúrgico representou $82,79 \%$; o têxtil/vestuário, $11,85 \%$; o químico-farmacêutico, $0,20 \%$; o frigorífico, $0,36 \%$; o de madeira/derivados, 3,46\%; o de fruticultura, $0,69 \%$; o de cachaça, $0,03 \%$; e outros, $0,23 \%$. Essas informações são visualizadas na tabela 3 . 
Tabela 3 - Norte de Minas Gerais: Os setores exportadores no período de $2004-2008$

\begin{tabular}{l|r|r|r|c}
\multicolumn{1}{c|}{ SETORES } & VALOR US\$ (DÓLAR) & \multicolumn{1}{c|}{$\%$} & \multicolumn{1}{c|}{ QUANTIDADE KG } & $\%$ \\
\hline Siderúrgico/metalúrgico & 1.183 .117 .109 & 62,25 & 712.841 .218 & 82,79 \\
\hline Têxtil/vestuário & 453.427 .266 & 23,85 & 102.266 .874 & 11,85 \\
\hline Químico farmacêutico & 217.989 .282 & 11,46 & 3.188 .670 & 0,20 \\
\hline Frigorífico & 16.806 .871 & 0,88 & 2.992 .033 & 0,36 \\
\hline Madeira/derivados & 9.415 .714 & 0,49 & 29.830 .158 & 3,46 \\
\hline Mineração1 & 6.772 .175 & 0,35 & 3.079 .248 & 0,36 \\
\hline Fruticultura & 3.259 .681 & 0,17 & 5.963 .455 & 0,69 \\
\hline Cachaça & 734.239 & 0,04 & 327.432 & 0,03 \\
\hline Outros & 8.911 .798 & 0,51 & 2.344 .480 & 0,26 \\
\hline Total & $\mathbf{1 . 9 0 0 . 4 3 4 . 1 3 5}$ & $\mathbf{1 0 0}$ & $\mathbf{8 6 2 . 8 3 3 . 5 6 8}$ & $\mathbf{1 0 0}$ \\
\hline
\end{tabular}

Fonte: MDIC, 2004; 2005; 2006; 2007; 2008.

Org. PEREIRA, Luiz Andrei Gonçalves, 2009.

(1) No setor de mineração, destaca-se que, no período analisado, a exportação de diamantes representou um valor financeiro de US\$ 6.019.640 (dólares) e a quantidade em peso somou apenas 4 quilos, ou seja, esse produto foi vendido no mercado internacional como preço médio aproximado em US\$ 1.500 .000 (dólares) o quilograma. O setor de granito exportou, em valores monetários, US\$ 752.535 (dólares) e a quantidade em peso, 3.079.244 quilos.

Na política de exportação regional, grande parte das exportações norte-mineiras é composta por produtos tradicionais, conhecidos como commodities, que apresentam valor agregado relativamente baixo, enquanto os produtos dos setores químico-farmacêutico e metalúrgico representam a categoria dos produtos de alto valor agregado. E para transportá-los foi utilizada a logística de transportes no percurso nacional e no percurso internacional. O transporte nacional é considerado a circulação de mercadorias do local de produção até os entrepostos logísticos. Os entrepostos logísticos são os terminais alfandegados ou não onde as mercadorias são embarcadas, desembaraçadas e/ou passam pelas fronteiras brasileiras. O transporte internacional é considerado o percurso a partir da ultrapassagem das fronteiras terrestres, marítimas e aéreas. Na análise dos dados, trabalhou-se com o agrupamento em categorias setoriais dos produtos exportados, considerando a modalidade de transporte nacional que cada empresa utilizou para levar os produtos até os entrepostos logísticos, qual entreposto logístico ela usou para desembaraço, embarque e/ou passagem das mercadorias. Depois da identificação do entreposto, foi possível saber por qual modalidade de transporte internacional os produtos transpuseram as fronteiras brasileiras. O quadro 1 mostra a estrutura da logística de transporte usada pelas empresas exportadoras localizadas na região norte-mineira.

Os resultados do quadro 1 nos levaram às seguintes considerações: No percurso nacional, o transporte rodoviário concentrou o escoamento de, aproximadamente, $89 \%$ dos valores financeiros, e $94,5 \%$ da quantidade em quilogramas. Nesse percurso, apenas uma empresa fez o uso do transporte ferroviário. O entreposto logístico mais utilizado foi o sistema portuário. Consequentemente, resultou em uma maior utilização do transporte marítimo internacional. Os pontos de fronteira são usados para desembaraço e/ou embarque dos lotes de mercadorias destinados à Argentina, Chile, Uruguai, Paraguai e Bolívia, resultando no uso do transporte rodoviário internacional. Apenas uma empresa (a empresa 43 do quadro 01) usou o transporte ferroviário em território boliviano. O aeroporto e o transporte aéreo internacional são utilizados para embarque dos pequenos lotes de mercadorias. Geralmente, apresentam um valor agregado considerável e necessitam de rapidez na entrega. 
PEREIRA, L. A. G.; LESSA, S. N.

Quadro 1 - Norte de Minas Gerais: A logística de transporte utilizada pelas empresas exportadoras

\begin{tabular}{|c|c|c|c|c|c|c|c|c|c|c|}
\hline \multirow{2}{*}{ SETORES } & \multirow{2}{*}{$\begin{array}{l}\text { NÜMERO } \\
\text { DAS } \\
\text { EMPRESAS }\end{array}$} & \multicolumn{2}{|c|}{$\begin{array}{l}\text { TRANSPORTE } \\
\text { NACIONAL }\end{array}$} & \multicolumn{3}{|c|}{ ENTREPOSTOS LOGISTICOS } & \multicolumn{4}{|c|}{ TRANSPORTE INTERNACIONAL } \\
\hline & & Rod. & Fer. & Porto & Aer & $\begin{array}{l}\text { Ponto de } \\
\text { Fronteira }\end{array}$ & Mar. & Aér. & Rod. & Fer. \\
\hline \multirow{10}{*}{ Siderúrgico /Metalúrgico } & 01 & $\mathrm{X}$ & 0 & 0 & $X$ & 0 & 0 & $X$ & 0 & 0 \\
\hline & 02 & $X$ & 0 & $\mathrm{X}$ & 0 & 0 & $\mathrm{X}$ & 0 & 0 & $\mathrm{O}$ \\
\hline & 03 & $X$ & 0 & $\mathrm{X}$ & $X$ & $X$ & $X$ & $X$ & $X$ & 0 \\
\hline & 04 & $X$ & 0 & $X$ & 0 & $\mathrm{X}$ & $X$ & 0 & $X$ & 0 \\
\hline & 05 & $X$ & 0 & $X$ & $X$ & 0 & $X$ & $X$ & 0 & 0 \\
\hline & 06 & $X$ & 0 & $X$ & 0 & 0 & $X$ & 0 & 0 & 0 \\
\hline & 07 & $\mathrm{X}$ & 0 & $\mathrm{X}$ & $\mathrm{O}$ & $\mathrm{X}$ & $\mathrm{X}$ & 0 & $\mathrm{X}$ & 0 \\
\hline & 08 & $X$ & 0 & $\mathrm{X}$ & $\mathrm{X}$ & $\mathrm{X}$ & $\mathrm{X}$ & $x$ & $\mathrm{X}$ & 0 \\
\hline & 09 & $X$ & 0 & $X$ & $X$ & $X$ & $X$ & $X$ & $X$ & 0 \\
\hline & 10 & $X$ & 0 & $\mathrm{X}$ & $\mathrm{X}$ & $\mathrm{X}$ & $\mathrm{X}$ & $\mathrm{X}$ & $\mathrm{X}$ & $\mathrm{O}$ \\
\hline \multirow{5}{*}{ Têxtil / Vestuário } & 11 & $X$ & 0 & $X$ & 0 & $X$ & $X$ & 0 & $X$ & 0 \\
\hline & 12 & $X$ & 0 & $\mathrm{X}$ & 0 & $X$ & $X$ & 0 & $X$ & 0 \\
\hline & 13 & $X$ & $x$ & $X$ & $\mathrm{O}$ & $\mathrm{X}$ & $\mathrm{X}$ & 0 & $X$ & 0 \\
\hline & 14 & $\mathrm{X}$ & 0 & $\mathrm{O}$ & O & $\mathrm{X}$ & O & 0 & $\mathrm{X}$ & O \\
\hline & 15 & $\mathrm{X}$ & 0 & $\mathrm{X}$ & 0 & 0 & $\mathrm{X}$ & 0 & 0 & 0 \\
\hline \multirow[b]{2}{*}{ Químico /Farmacêutico } & 16 & $\mathrm{X}$ & 0 & $\mathrm{X}$ & $\mathrm{X}$ & 0 & $\mathrm{X}$ & $\mathrm{X}$ & 0 & 0 \\
\hline & 17 & $\mathrm{X}$ & 0 & $\mathrm{X}$ & $\mathrm{X}$ & $x$ & $\mathrm{X}$ & $\mathrm{X}$ & $\mathrm{X}$ & 0 \\
\hline Frigorífico & 18 & $\mathrm{X}$ & 0 & $\mathrm{X}$ & 0 & 0 & $\mathrm{X}$ & 0 & 0 & 0 \\
\hline \multirow{6}{*}{ Madeiras /Derivados } & 19 & $X$ & 0 & $x$ & 0 & 0 & $X$ & 0 & 0 & 0 \\
\hline & 20 & $\mathrm{X}$ & 0 & $\mathrm{X}$ & $\mathrm{O}$ & 0 & $\mathrm{X}$ & 0 & 0 & 0 \\
\hline & 21 & $\mathrm{X}$ & 0 & $\mathrm{X}$ & $\mathrm{O}$ & 0 & $\mathrm{X}$ & 0 & 0 & 0 \\
\hline & 22 & $X$ & 0 & $\mathrm{X}$ & 0 & 0 & $\mathrm{X}$ & 0 & 0 & 0 \\
\hline & 23 & $X$ & 0 & $X$ & 0 & 0 & $X$ & 0 & 0 & 0 \\
\hline & 24 & $X$ & 0 & $X$ & 0 & 0 & $X$ & 0 & 0 & 0 \\
\hline \multirow{4}{*}{ Mineração } & 25 & $\mathrm{X}$ & 0 & $\mathrm{X}$ & $\mathrm{O}$ & 0 & $\mathrm{X}$ & 0 & 0 & 0 \\
\hline & 26 & $\mathrm{X}$ & 0 & $\mathrm{X}$ & $\mathrm{O}$ & 0 & $\mathrm{X}$ & 0 & 0 & 0 \\
\hline & 27 & $X$ & 0 & $X$ & $\mathrm{O}$ & 0 & $X$ & 0 & 0 & 0 \\
\hline & 28 & $\mathrm{X}$ & 0 & $\mathrm{X}$ & $\mathrm{O}$ & 0 & $\mathrm{X}$ & 0 & 0 & 0 \\
\hline \multirow[t]{2}{*}{ Fruticultura } & 29 & $X$ & 0 & $X$ & 0 & 0 & $X$ & 0 & 0 & 0 \\
\hline & 30 & $X$ & 0 & $X$ & 0 & 0 & $X$ & 0 & 0 & 0 \\
\hline \multirow{6}{*}{ Cachaça } & 31 & $\mathrm{X}$ & 0 & $\mathrm{X}$ & 0 & 0 & $\mathrm{X}$ & 0 & 0 & 0 \\
\hline & 32 & $X$ & 0 & $X$ & $X$ & 0 & $X$ & $X$ & 0 & 0 \\
\hline & 33 & $X$ & 0 & $X$ & 0 & 0 & $X$ & 0 & 0 & 0 \\
\hline & 34 & $\mathrm{X}$ & 0 & 0 & 0 & $\mathrm{X}$ & 0 & $\mathrm{O}$ & $\mathrm{X}$ & 0 \\
\hline & 35 & $X$ & 0 & $X$ & 0 & 0 & $X$ & 0 & 0 & 0 \\
\hline & 36 & $X$ & 0 & $X$ & 0 & 0 & $X$ & 0 & 0 & 0 \\
\hline \multirow{9}{*}{ Outros } & 37 & $X$ & 0 & 0 & $x$ & 0 & 0 & $x$ & 0 & 0 \\
\hline & 38 & $X$ & 0 & $X$ & 0 & 0 & $X$ & 0 & 0 & 0 \\
\hline & 39 & $X$ & 0 & 0 & $X$ & $X$ & 0 & $X$ & $X$ & 0 \\
\hline & 40 & $X$ & 0 & $X$ & $\mathrm{O}$ & $X$ & $X$ & 0 & $X$ & 0 \\
\hline & 41 & $X$ & 0 & $X$ & 0 & 0 & $X$ & 0 & 0 & 0 \\
\hline & 42 & $X$ & 0 & $X$ & 0 & 0 & $X$ & 0 & 0 & 0 \\
\hline & 43 & $X$ & 0 & $X$ & 0 & $X$ & $X$ & 0 & 0 & $X$ \\
\hline & 44 & $X$ & 0 & $X$ & 0 & 0 & $X$ & 0 & 0 & 0 \\
\hline & 45 & 0 & 0 & 0 & 0 & 0 & 0 & 0 & 0 & 0 \\
\hline
\end{tabular}

Legenda $=\mathrm{X}$ indica a utilização dos modais de transportes nacional, internacional e os entrepostos logísticos. $\mathrm{O}$ indica a não utilização dos modais de transportes nacional, internacional e os entrepostos logísticos.

Fonte: Pesquisa de campo, realizada em Janeiro - Fevereiro de 2010.

Elaborado por: PEREIRA, Luiz Andrei Gonçalves, 2010. 
As empresas da região norte-mineira fizeram um grande uso do sistema portuário e do transporte marítimo internacional. Espacialmente, as empresas do setor siderúrgico/metalúrgico fizeram um grande uso do porto do Rio de Janeiro, seguido pelos portos de Santos e de Sepetiba. O setor têxtil/vestuário usou muito o porto de Santos, seguido do porto de Salvador e de Suape. O setor químico-farmacêutico embarcou grande parte de suas cargas nos portos de Sepetiba e de Santos. O setor frigorífico usou muito o porto de Santos, e, em uma proporção menor, o porto de Itajaí. O Setor madeiras/derivados utilizou muito o porto de Salvador, seguido pelo porto de Santos. O setor de mineração usou somente os portos capixabas de Tubarão e de Vitória. O setor de fruticultura utilizou os portos de Santos e de Salvador. O setor de cachaça usou os portos de Santos, de Salvador, do Rio de Janeiro e de Suape. Os outros setores usaram os portos de Santos e do Rio de Janeiro. No caso de embarque de pequenos volumes de cargas que exigiam rapidez nas entregas, as empresas optaram por embarcá-los nos aeroportos de Confins, de Guarulhos e de Viracopos. Os volumes de cargas que exigiam rapidez nas entregas foram enviados por transporte rodoviário internacional para os países do MERCOSUL (Argentina, Paraguai e Uruguai), Chile e Bolívia. A figura 3 mostra a espacialização da logística de transporte regional que as empresas exportadoras utilizaram para ter acesso aos entrepostos logísticos e para fazer conexão com o sistema logístico internacional. Enquanto a figura 4 visualiza os fluxos dos setores exportadores do local produção até os entrepostos logísticos.

Nas análises anteriores, buscou-se uma compreensão da complexidade da logística de transporte voltada para o setor de exportações na mesorregião norte de Minas Gerais. Sendo assim, as distâncias são superadas por transportes terrestres (rodovia e ferrovia) até os entrepostos logísticos. Após os entrepostos logísticos, as mercadorias norte-mineiras transpõem as fronteiras brasileiras por transporte aéreo, rodoviário, ferroviário e marítimo. Grande parte das mercadorias sai por via marítima. Depois de fazer a transposição das fronteiras brasileiras os produtos brasileiros norte-mineiros seguiram para o mercado externo. Sendo assim, os países importadores das mercadorias do norte de Minas estão agrupados em blocos econômicos regionais: União Europeia , NAFTA, APEC (excluso países do NAFTA), MERCOSUL e outros. A figura 5 destaca a espacialização de blocos regionais dos mercados compradores dos produtos fabricados na região norte de Minas Gerais, bem como indica os valores financeiros, moeda corrente, exportados para cada mercado.

No período analisado, de 2004 - 2008, o norte de Minas exportou, em valores financeiros, o total de US\$ 1.900.434.135 (dólares), que representa $0,3 \%$ das exportações brasileiras e 2,5\% das exportações do estado de Minas Gerais. Sendo assim, na subdivisão desses valores, o norte de Minas teve como maior mercado importador a União Europeia, que importou US\$ 818.963.373 (dólares), o NAFTA como segundo maior mercado, que comprou US\$ 597.396 .053 (dólares), a APEC como terceiro mercado, importando US\$ 188.733 .053 (dólares). O quarto maior comprador foi o MERCOSUL, com US\$185.424.723 (dólares), e outros mercados compraram cerca de US\$109.916.933 (dólares). Esses valores monetários foram escoados por diferentes infraestruturas logísticas de transportes para o mercado internacional. Na seqüencia serão apresentados os principais problemas logísticos enfrentados pelos setores exportadores da região norte-mineira e as possíveis soluções logísticas para eficiência e eficácia da circulação da produção exportada, bem como a redução das avarias, dos custos logísticos e a maximização dos lucros na política de exportação norte-mineira.

Na política de exportação brasileira, é um grande desafio transportar as mercadorias das áreas interioranas para os entrepostos logísticos, e, consequentemente, colocá-las no mercado internacional a um preço competitivo. Na mesorregião norte de Minas Gerais, também não é diferente; existem diversos problemas que são empecilhos no escoamento da produção regional destinada ao mercado externo, como: A) Má conservação das rodovias; B) precariedade e baixa cobertura do sistema ferroviário; C) falta de serviços logísticos especializados; D) burocracia no desembaraço das mercadorias; E) falta de transporte aéreo de cargas; F) falta de infraestrutura de apoio rodovi- 


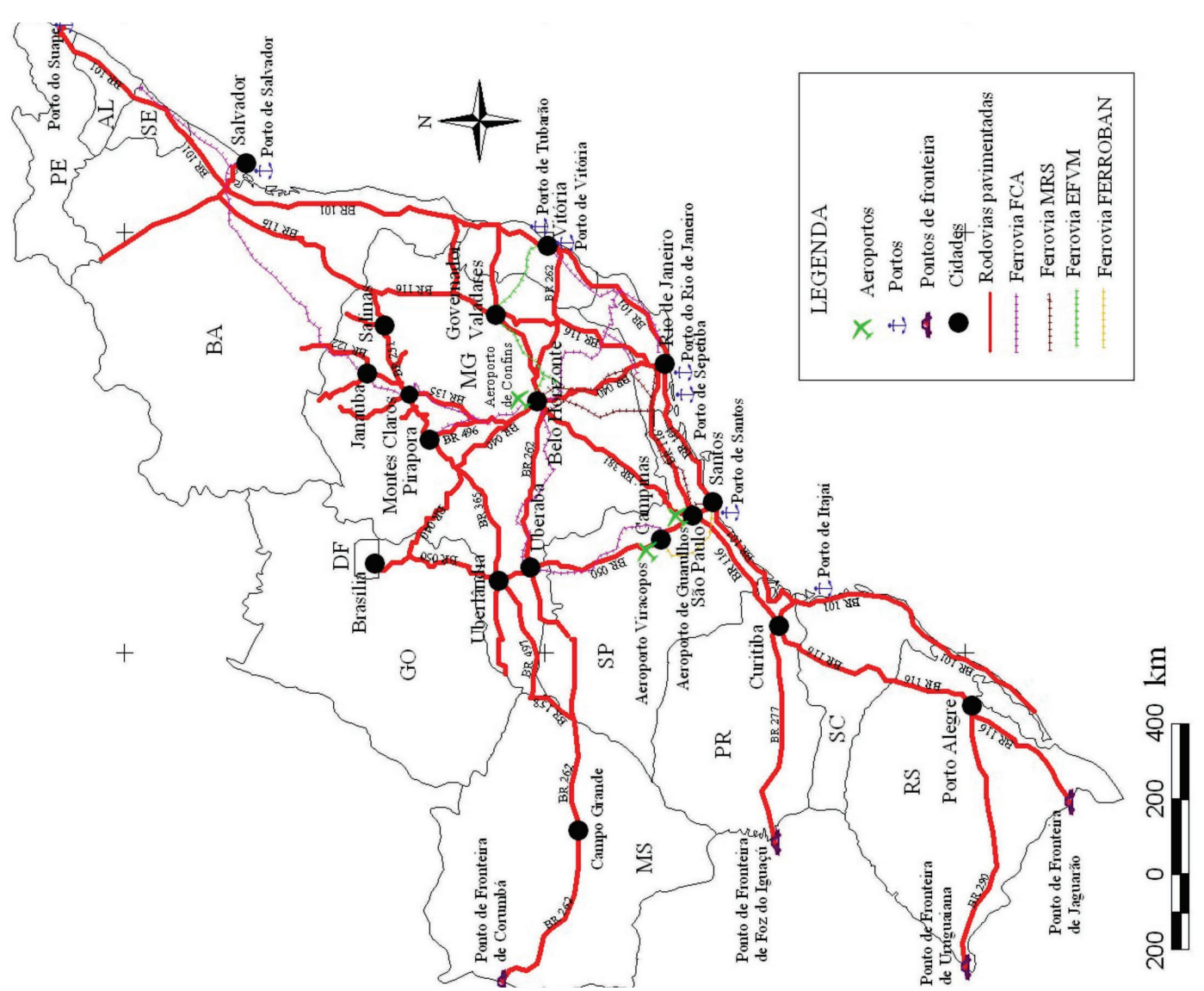

Figura 3 - Logística e transporte dos setores exportadores localizados na mesorregião norte de Minas Gerais Fonte. DNIT, 2009. Org. PEREIRA, Luiz Andrei Gonçalves, 2009.

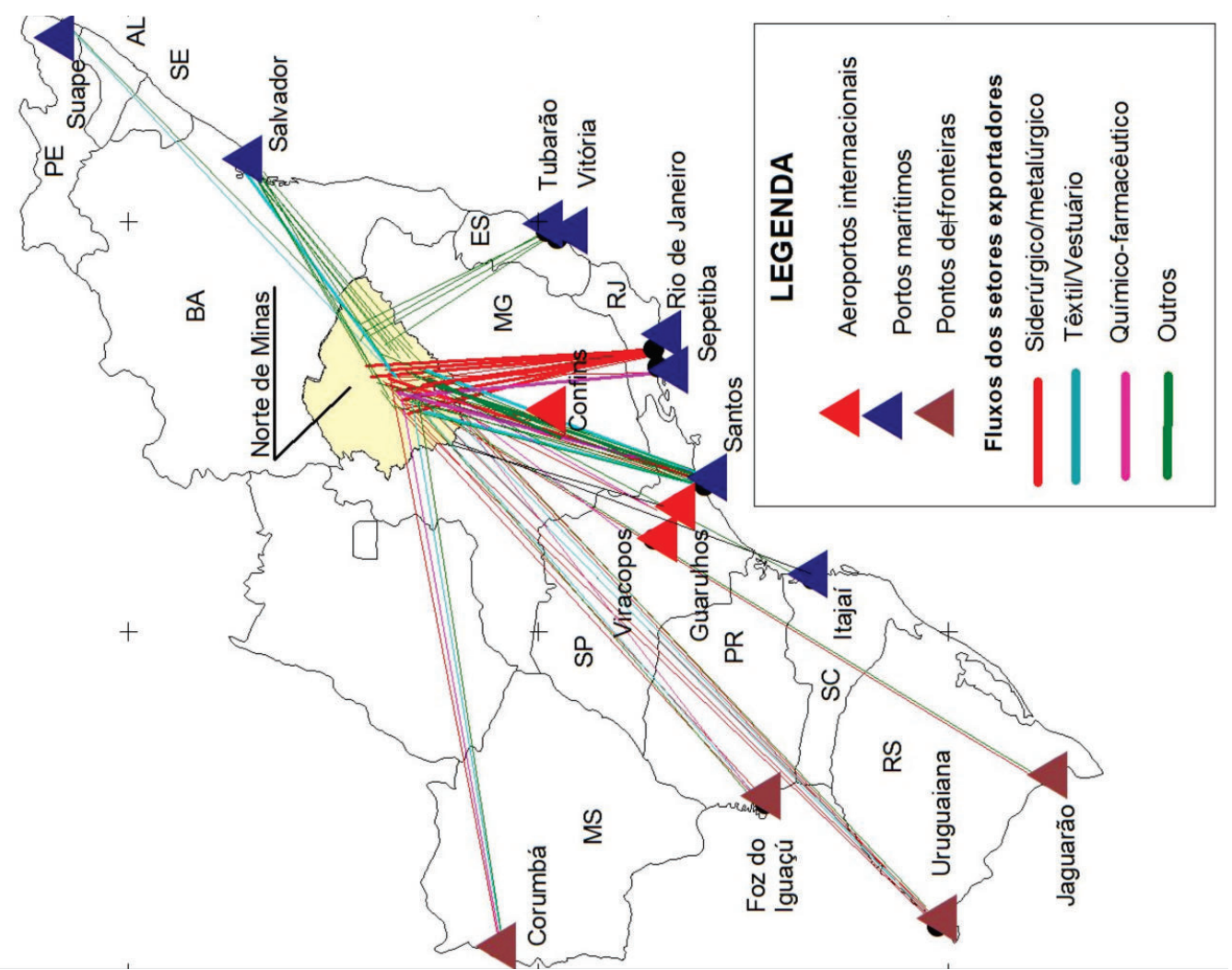

Figura 4 - Fluxos dos setores exportadores no norte de Minas Gerais: sentido local de produção - entrepostos logísticos

Fonte: Pesquisa de campo, realizada em janeiro - fevereiro de 2010.

Elaborado por: PEREIRA, Luiz Andrei Gonçalves, 2009. 
ário nas margens das rodovias; G) falta de uma Estação Aduaneira Interior - EADI (porto seco); H) deficiências na infraestrutura logística portuária.

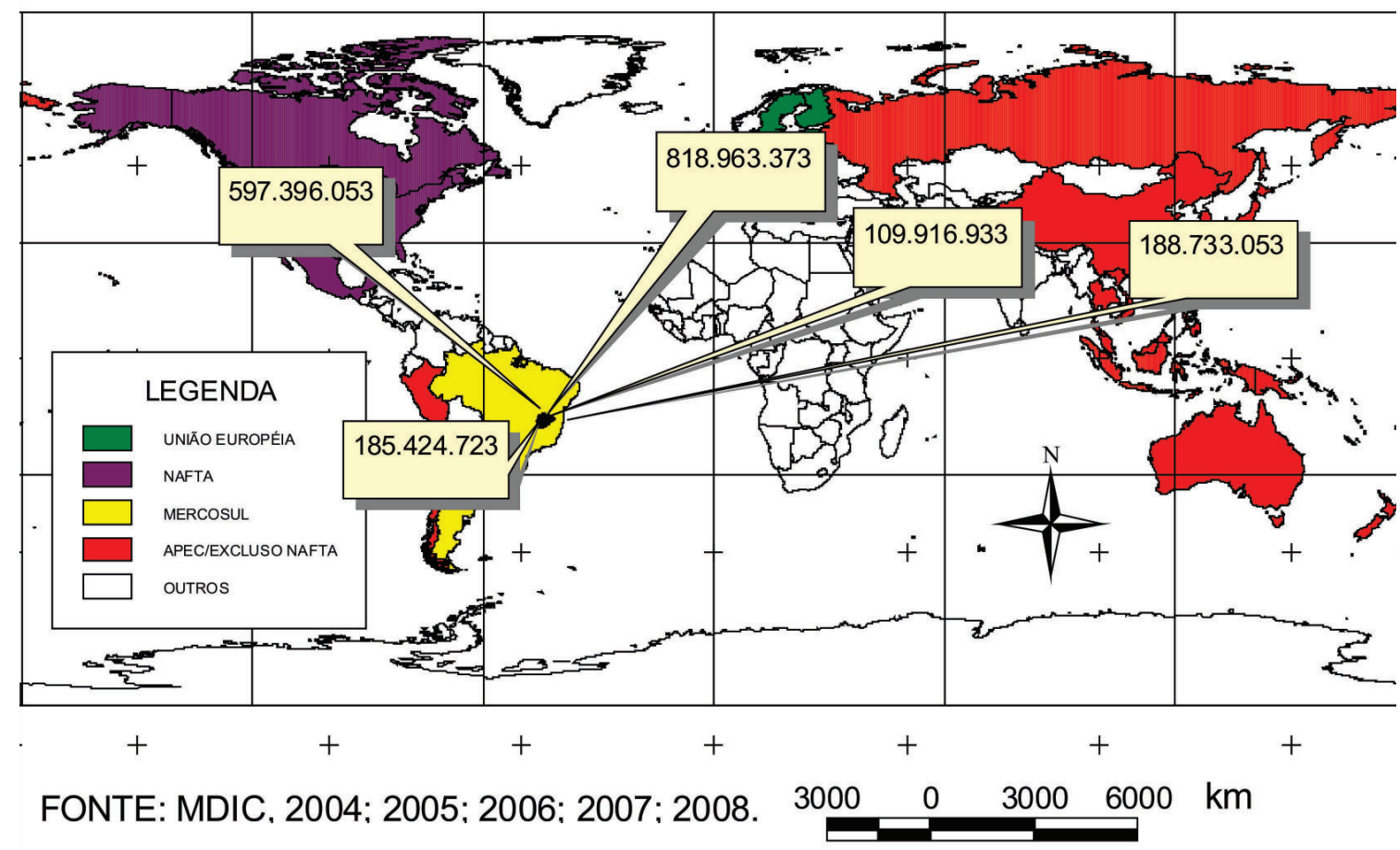

Figura 5 - Mapa do Norte de Minas: Destino das exportações no período de 2004 - 2008 (US\$ - FOB). Fonte: MDIC, 2004; 2005; 2006; 2007; 2008.

Org. PEREIRA, Luiz Andrei Gonçalves, 2008.

Existem diversos problemas na infraestrutura de transporte regional que são empecilhos no escoamento da produção destinada ao mercado externo. Sendo assim, é um grande desafio a superação desses entraves, que se tornará um fator importante na maximização da eficiência e da eficácia da logística de transporte voltada para os setores de exportações regionais. Neste sentido, as possíveis soluções logísticas para a região norte-mineira podem ser elencadas em: A) Programa contínuo de investimentos na infraestrutura rodoviária; B) investimentos na modernização do sistema ferroviário; C) implantação de transporte aéreo de cargas; D) criação de infraestrutura de apoio às margens das rodovias; E) mais oferta de serviços logísticos especializados, F) modernização do sistema aduaneiro; G) instalação de uma EADI (porto seco); H) programa contínuo de modernização do sistema portuário.

\section{CONSIDERAÇÕES FINAIS}

Na política de planejamento e de desenvolvimento regional implementada pelas ações estatais, a infraestrutura e a atividade de transporte refletiram no ordenamento espacial das atividades econômicas da mesorregião norte de Minas Gerais, na qual se observa uma concentração das atividades industriais, agropecuárias e agroindustriais nos pontos mais dinâmicos do território, e que tem uma maior facilidade em conectar-se com o sistema capitalista nacional e internacional. O processo de modernização econômica pode ser demonstrado nas atividades industriais em Montes Claros, Pirapora, Várzea da Palma, Bocaiuva e Capitão Enéas. E também nos projetos agroindustriais, pecuária, irrigação e silvicultura, nos municípios de Jaíba, Nova Porteirinha, Janaúba, Pirapora, Grão-Mogol e Salinas, entre outros. 
A concentração espacial das atividades produtivas refletiu também na concentração dos municípios exportadores do norte de Minas, onde cinco municípios exportam, aproximadamente, 98\% da produção regional. Na região, os setores tradicionais da economia, os de produtos siderúrgicos, têxteis, agroindustriais e mineração são os setores que mais exportaram em termos de valores monetários e de quantidade em peso. Esses produtos apresentam valores agregados relativamente baixos. Os setores siderúrgicos e têxteis estão mais bem estruturados nos padrões do comércio internacional, enquanto o setor agroindustrial e de mineração está começando a ingressar no mercado externo. A exportação de carne in natura apresentou uma maior inserção no mercado europeu e asiático. Os setores químico-farmacêutico e metalúrgico também estão inseridos nos moldes da estrutura capitalista de comércio exterior. São os exportadores de produtos tecnológicos de alto valor agregado, especialmente a exportação de produtos para a saúde humana. Os setores voltados para as atividades agrícolas e de mineração exportaram produtos de valores agregados baixos, com exceção da exportação de diamantes, que apresentaram muitos problemas na área de comercialização e logística para atuar no mercado externo.

De forma geral, na política de exportação norte-mineira, a estrutura logística de transportes que faz o escoamento da produção destinada ao mercado externo está concentrada no transporte rodoviário (percurso nacional), no terminal portuário e no transporte marítimo internacional. Esta estrutura intermodal de transportes apresenta menores custos operacionais, tornando-se uma preferência das empresas na política de exportação. As deficiências do sistema logístico tornaram-se um dos empecilhos que encarecem os custos finais dos produtos, dificultam a contratação de transportadora na região, uma vez que o setor da logística de transporte regional é pouco dinâmico. A prova disso é que as empresas localizadas na região contratam os serviços logísticos de transportes especializados em outras regiões do estado de Minas Gerais e do país, especialmente nas cidades de Santos, São Paulo, Rio de Janeiro, Salvador, Sete Lagoas, Belo Horizonte, Vitória, entre outras. Esse fator demonstra a fragilidade do sistema logístico e o pouco dinamismo do empresariado regional em investir na criação de empresas especializadas em logística de transporte para atender ao mercado nacional e internacional. Outro fator que é um empecilho para a exportação é o fato de a região norte-mineira ser produtora de commodities, produtos de grande quantidade em peso e de baixo valor agregado, que apresentam custos logísticos significativos no preço final do produto, o que, praticamente, inviabiliza as exportações pelas pequenas empresas. Assim, seria interessante os pequenos empresários buscarem agregar valor aos produtos regionais, investindo na industrialização e no marketing desses produtos, com o intuito de conquistar novas oportunidades no mercado internacional.

\section{AGRADECIMENTOS}

Ao ETENE/Banco do Nordeste do Brasil - BNB, pelo auxílio financeiro para realização desta pesquisa.

\section{REFERÊNCIA BIBLIOGRÁFICA}

BRASIL. Decreto n 9.256, de 28 de dezembro de 1911.

BRASIL. Decreto-Lei n⿳0 9.857, de 13 de Setembro de 1946.

BRASIL. Decreto-Lei no 8.031, de 03 de Outubro de 1945.

BRASIL. Lei $\mathbf{n}^{\circ} \mathbf{5 4 1}$, de 15 de dezembro de 1948.

BRASIL. Lei no 1.649, de 19 de Julho de 1952.

BRASIL. Lei $\mathbf{n}^{0}$ 3.692, de 15 de Dezembro de 1959.

COHN, Amélia. Crise regional e planejamento: o processo de criação da SUDENE. São Paulo: Perspectiva, 1978. 
DEPARTAMENTO DE ESTRADAS DE RODAGENS - DER. Mapa rodoviário de Minas Gerais. Belo Horizonte: DER-MG, 2009.

DEPARTAMENTO NACIONAL DE INFRAESTRUTURA DE TRANSPORTES - DNIT. Mapas multimodais: Mapa rodoviário do Brasil. Brasília: DNIT, 2009. Disponível em: <www.dnit.gov.br>. Acesso em: 05 jan. 2010.

EMPRESA BRASILEIRA DE PLANEJAMENTO DE TRANSPORTES - GEIPOT. Caminhos do Brasil. Brasília: GEIPOT, 2001.

FRIEDMAN, John. Planejamento regional: Problema de integração espacial. Trad. Rui César Santos. In: SCHWARTZMAN, Jacques (Org.). Economia regional. Belo Horizonte: CEDEPLAR, 1977.

FUNDAÇÃO JOÃO PINHEIRO - FJP. Área Mineira da Sudene: $1^{\circ}$ Encontro de Planejamento Regional. Belo Horizonte: FJP, 1975.

HENRIQUES, Márcio Olympio Guimarães. A problemática regional nos planos brasileiros. In: SCHWARTZMAN, Jacques (Org.). Economia regional: Textos escolhidos. Belo Horizonte: CEDEPLAR, 1977.

MATTOS, Carlos A. de. Notas sobre o planejamento regional em escala nacional. Trad. Solange Barbi Resende. In: SCHWARTZMAN, Jacques (Org.). Economia regional: Textos escolhidos. Belo Horizonte: CEDEPLAR, 1977.

MINISTÉRIO DO DESENVOLVIMENTO INDÚSTRIA E COMÉRCIO EXTERIOR - MDIC. Estatísticas do comércio exterior: Empresas exportadoras. Brasília: MDIC, 2004. Disponível em <www.mdic.gov.br>. Acesso em: 15 jan. 2009.

MINISTÉRIO DO DESENVOLVIMENTO INDÚSTRIA E COMÉRCIO EXTERIOR - MDIC. Estatísticas do comércio exterior: Empresas exportadoras. Brasília: MDIC, 2005. Disponível em $<$ www.mdic. gov.br>. Acesso em: 15 jan. 2009.

MINISTÉRIO DO DESENVOLVIMENTO INDÚSTRIA E COMÉRCIO EXTERIOR - MDIC. Estatísticas do comércio exterior: Empresas exportadoras. Brasília: MDIC, 2006. Disponível em <www.mdic. gov.br>. Acesso em: 15 jan. 2009.

MINISTÉRIO DO DESENVOLVIMENTO INDÚSTRIA E COMÉRCIO EXTERIOR - MDIC. Estatísticas do comércio exterior: Empresas exportadoras. Brasília: MDIC, 2007. Disponível em <www.mdic. gov.br>. Acesso em: 15 jan. 2009.

MINISTÉRIO DO DESENVOLVIMENTO INDÚSTRIA E COMÉRCIO EXTERIOR - MDIC. Estatísticas do comércio exterior: Empresas exportadoras. Brasília: MDIC, 2008. Disponível em <www.mdic. gov.br>. Acesso em: 15 jan. 2009.

MINISTÉRIO DO DESENVOLVIMENTO INDÚSTRIA E COMÉRCIO EXTERIOR - MDIC. Balança comercial por município. Brasília: MDIC, 2004. Disponível em <www.mdic.gov.br>. Acesso em: 16 jan. 2009. MINISTÉRIO DO DESENVOLVIMENTO INDÚSTRIA E COMÉRCIO EXTERIOR - MDIC. Balança comercial por município. Brasília: MDIC, 2005. Disponível em <www.mdic.gov.br>. Acesso em: 16 jan. 2009. MINISTÉRIO DO DESENVOLVIMENTO INDÚSTRIA E COMÉRCIO EXTERIOR - MDIC. Balança comercial por município. Brasília: MDIC, 2006. Disponível em <www.mdic.gov.br>. Acesso em: 16 jan. 2009. MINISTÉRIO DO DESENVOLVIMENTO INDÚSTRIA E COMÉRCIO EXTERIOR - MDIC. Balança comercial por município. Brasília: MDIC, 2007. Disponível em <www.mdic.gov.br>. Acesso em: 16 jan. 2009. MINISTÉRIO DO DESENVOLVIMENTO INDÚSTRIA E COMÉRCIO EXTERIOR - MDIC. Balança comercial por município. Brasília: MDIC, 2008. Disponível em <www.mdic.gov.br>. Acesso em: 16 jan. 2009. MONTES CLAROS. Secretaria de Planejamento - SEPLAN. Projeto cidades de porte médio: Sub-projeto de Montes Claros vol. 1. Montes Claros: SEPLAN, 1978.

OLIVEIRA, Marcos Fábio Martins de. O processo de formação de Montes Claros e da Área Mineira da SUDENE. In: OLIVEIRA, Marcos Fábio Martins de. RODRIGUES, Luciene (Org.). Formação social e econômica do Norte de Minas. Montes Claros: Editora UNIMONTES, 2000.

OLIVEIRA, Marcos Fábio Martins de. O Processo de desenvolvimento de Montes Claros (MG), sob a orientação da SUDENE (1960 - 1980). Dissertação (Mestrado em História Econômica) - Programa de Pós-Graduação em História Econômica, Universidade de São Paulo - USP, São Paulo, 1996. 
OLIVEIRA, Marcos Fábio Martins de. O nascimento do FNE - Fundo Constitucional de Financiamento do Nordeste. Revista Caminhos da História. Montes Claros: Departamento de História - UNIMONTES, vol. 12, $\mathrm{n}^{\mathrm{o}}$. 1, 2007.

PEREIRA, Laurindo Mékie. Em nome da região, a serviço do capital: O regionalismo político norte-mineiro. Tese (Doutorado em História) - Programa de Pós-Graduação em História Econômica, Universidade de São Paulo - USP, São Paulo, 2007.

PEREIRA, Anete Marília. Cidade média e região: O significado de Montes Claros no norte de Minas Gerais. Tese (Doutorado em Geografia) - Instituto de Geografia, Universidade Federal de Uberlândia - UFU, Uberlândia, 2007.

REIS, Geraldo Antônio dos. Algumas considerações sobre o processo de desenvolvimento recente da região Mineira do Nordeste. In: SANTOS, Gilmar Ribeiro dos. Trabalho, cultura e sociedade no Norte de Minas / Noroeste de Minas. Montes Claros: Best Comunicação e Marketing, 1997.

RODRIGUES, Luciene. A formação econômica do norte de Minas e o período recente. In: OLIVEIRA, Marcos Fábio Martins de. RODRIGUES, Luciene (Org.). Formação social e econômica do Norte de Minas. Montes Claros: Editora UNIMONTES, 2000.

RODRIGUES, Luciene. Traços e cronologia do planejamento para o desenvolvimento no Brasil. Revista Caminhos da História. Montes Claros: Departamento de História - UNIMONTES, v. 4, n. 4, 1999.

ROMO, Carlos Matus. O espaço físico na política de desenvolvimento. Trad. João Antônio de Paula. In: SCHWARTZMAN, Jacques (Org.). Economia regional. Belo Horizonte: CEDEPLAR, 1977.

SOUZA, João Gonçalves de. O Nordeste brasileiro. Fortaleza: BNB, 1979.

SUPERINTENDÊNCIA DO DESENVOLVIMENTO DO NORDESTE - SUDENE. I plano diretor de desenvolvimento econômico e social do nordeste 1961-1963. Recife: SUDENE, 1966 a.

SUPERINTENDÊNCIA DO DESENVOLVIMENTO DO NORDESTE - SUDENE. II plano diretor de desenvolvimento econômico e social do nordeste 1963 - 1965. Recife: SUDENE, 1968 a.

SUPERINTENDÊNCIA DO DESENVOLVIMENTO DO NORDESTE - SUDENE. III plano diretor de desenvolvimento econômico e social do nordeste 1965 - 1968. Recife: SUDENE, 1966 b.

SUPERINTENDÊNCIA DO DESENVOLVIMENTO DO NORDESTE - SUDENE. IV plano diretor de desenvolvimento econômico e social do nordeste 1969 - 1973. Recife: SUDENE, 1968 b.

SUPERINTENDÊNCIA DO DESENVOLVIMENTO DO NORDESTE - SUDENE. Incentivos fiscais. Recife: SUDENE, 2009. Disponível em <www.sudene.gov.br>. Acesso em: 12 jan. 2010.

Trabalho enviado em maio de 2011

Trabalho aceito em julho de 2011 